\title{
Assessing the Experience of Universities' Online Admission in Egypt: An Experiment Conducted during the COVID-19
}

\author{
Hend Abd El Halim ${ }^{1 *}$ Sara Beshir ${ }^{2}$ \\ 1. Business Information Systems Department, College of Management and Technology, Arab Academy \\ for Science and Technology and Maritime Transport (AASTMT), Alexandria, Egypt \\ 2. Master Degree in Business Administration (Academic MBA), Alexandria, Egypt \\ * E-mail of the corresponding author: hend a@aast.edu
}

\begin{abstract}
The research aims to test selected universities' websites in Egypt by conducting an experiment on the on-line admission process experiments during the COVID-19. The sample exceeds $60 \%$ (16) universities of total national and private universities chosen randomly. The invited participants were high school graduates who seek information about universities and apply on-line. They are participating while applying the on-line, the data were collected by three rounds demanding to reach the highest number of participants ended by receiving 73 valid experiments. Summing -up with the answers research questions were obtained by analyzing the received valid data. Universities' websites investigated against information criteria. Moreover, ranking them based on time to find applying-online, then to perform the activity. The research results revealed universities' interest in updating websites and accessibility of on-line admission across universities' websites, meanwhile, for applying-online activity time to find and to perform were varied through the same universities' websites.

Keywords: Online, Admission, Experiment, the COVID-19, national and private Universities' Websites, Egypt,
\end{abstract} Apply On-line, Higher Education (HE), Applicants, Information Criteria

DOI: $10.7176 / \mathrm{JAAS} / 69-06$

Publication date:December $31^{\text {st }} 2020$

\section{Introduction}

Examining the influence of the COVID-19 is not an optional issue in certain sectors i.e. medical care, and education. Higher Education (HE) that witnesses some changes such as transfer to e-learning provides instance electronic communication, and contact as subsets of their emergencies and crisis management plans. Nevertheless of distance learning negative impact was observed in the absence of direct contact between students and staff members. Affected in student's achievement, commitment, besides attrition as (Kennedy \& Ferdig, 2018) have reported. The situation before and during the COVID-19 in medical education was concerned in (Hilburg et al, 2020) as one of the recent researches examining the COVID-19 influences on a specific sector.

A respected number of students are enrolled in national and private universities in Egypt, 53125 students in June 2009, and 186181 in June 2019 with 133056 students increased during a decade, 165098 students in June 2020 (Information and Decision Support Center System, 2020a). In Egypt the number of national and private universities increased from 4 to 23 universities in two decades from June 1997: June 2017; three more universities added to reach 26 in June 2020 (Information and Decision Support Center System, 2020b).

Universities' websites are not only the virtual gates of universities but also the initial source of information. This may encourage universities to invest in their websites. Having the option of admission on-line facilities the availability of the process any time, form anywhere which enhances the productivity and outcomes of the process. The authority of this facility in the university's website and during COVID-19 specifically justified the need to assess the on-line admission / applying on-line facility in some websites facilities and services. The assessment targets improving the current websites to attract more visitors, save websites' visitors and users' time and efforts, and make websites offered services accessible using a safe and convenient way during COVID-19 in particular. 


\section{Research Aim and Problem}

Most of the examined universities' websites (16) were included in the evolution of these websites against determined the available information criteria being up to date, accurate, completed, and have applying on-line facility accessible. The research participants were invited to visit the intended websites and provide their view toward the above-mentioned information criteria. Also, they were asked to register the times they took till found an on-line admission option and how long it took to complete the process. Concerning the measurement of this activity - on-line admission was triggered by the desired researches on this issue resulted from the COVID-19 crises consequences. The inclusion of over $60 \%$ of the total number of non-governmental universities enriches the assessment process and provides information on this portion of national and private universities, which may end by having some common factors/information in generic. The COVID-19 acknowledged the significance of having a completed, updated, and easy to access and use the website for running core businesses activities electronically neither on a partial nor full base; it has become not a luxury option to have. HE sector has been severely impacted by the COVID-19, has the same urgently requirements to manage the crisis consequences. This creates a need to assess the private universities' websites currently used to stand on the appropriate applied actions, and invest in the observed success stories on the same.

\section{Literature Review - Background}

The COVID-19 triggered a new scale for technology adoption, which resulted in controlled user computer technology selection and acceptance of computer technology. Before the pandemic, the end-user in HE in Egypt has been considered regarding tools selection, adoption intention, and computer technology acceptance in (Abd El Halim, 2019), and existing associations were defined. These relationships may have changed due to COVID-19. This resulted in new researches becomes needed. Having this concern, in (Hilburg et al, 2020) the undergraduate and graduate medical education effects in organization and delivery that were resulted from the COVID-19 were indicated. The organization and delivery were not the only COVID-19 reported changes but also the learning environment and required experiences. Consequently, an enlargement in the usage of technological applications and tools that support learner contacts/ connections i.e. video conferencing has been observed by (Zhu et al, 2020) Additionally, offering some services in a digital form is one of the COVID-19 identified influences, between the digital applicable services digital library services in a university (Mehta \& Wang, 2020). In the same context, Kuwait University investigated by (Hendal, 2020) in regards to digital resource usage. This aligned with (Maxwell Library, Bridge water State University, 2020) who clarified that in HE a pandemic revolution exceeds being online to offer the virtual academic libraries services. In response to pandemic needs, a novel page- "The Coronavirus and Library Services" was developed in addition to improving the library's home page services defined as pandemic needs that concluded brainstormed of librarians' (Maxwell Library, Bridge water State University, 2020).

The technology provides room for a sustained communication that was reported amongst the COVID-19 crisis difficulties in (Peterson et al, 2020). As (Garrison \& Arbaugh ,2007) defined hidden curriculum as an emerging theme in our data as throughout the inquiry phase when teachers considering a technology a constant, coursework interaction can be considered effectively a practical learning goal. Although the negative social impact of distance learning on education stakeholders - staff members and students in forms of isolation and disconnection, it is still a compulsory alternative (Kennedy \& Ferdig, 2018). They added that distance learning social impact can be observed in aspects such as student's progress and commitment (Kennedy \& Ferdig, 2018). Another view was regarding the online learning impacts presented by (Lehman \& Conceicao, 2010), they acknowledged influencing positively on learning due to the teacher social presence (Lehman \& Conceicao, 2010).Focusing on social and emotional development and communication significance in both physical and virtual classrooms in more investigations is justified based on (Rice \& Kipp, 2020).

As (Bao, 2020) suggested different handling of online teaching resulted in students' anxiety. Besides, stressing the significance of a regular inquiry reconsideration to preserve a prompt reply to handy resources, which highlighted by highly performed instructors for the period of a distance emergency teaching as offered by (Whittle et al, 2020) 
The study added that during the crisis the students' influences i.e. home conditions, parents' engagement, and nonacademic that were demonstrated from the daily students' contacts (Whittle et al, 2020)

Universities responded to the COVID pandemic through designing plans of "Emergency Management Plan (EMP)," "Emergency Response Plan," "Crisis Management Plan," "Business Continuity Plan (BCP)" to demonstrate and outline the handling emergencies procedures (Izumi et al, 2020). In the same trend, the differences between pre-planned online learning and Emergency Remote Teaching Environments ERTEs was discussed in (Hodges et al, 2020) and (Trust, 2020) who emphasized the attention to accessibility, equity, digital divides, privacy and security aspects which ERTE underlined. ERTEs were stated as for the period of crisis - a developed tentative instructional manual (Hodges et al, 2020).

Additionally, having an overall iterative assessment of the remote teaching process is a part of the ERTE framework as mentioned by (Hodges et al, 2020) When an ERTE is applied; facilitating agency is provided by learning goals and instructional methods (Whittle et al, 2020)

The contingency plans development importance was stressed to be conducted before offering potential problems solutions by (Bao, 2020) who investigated online education on an abnormally/ exceptionally large scale. The recognition of learning environment modules in the Cambridge Learning Sciences Handbook; learning environment modules consist of people in the environment, technologies, architecture, and room layout, and the physical objects within and the social and cultural environment as reported by (Sawyer, 2005). In the same context, online course quality matter has been specified in (Xu el al, 2020).

On the other side, the online learning during the pandemic supporting attempts such as a set of inquiries and replies of lecturers have been delivered as an outcome of an initiative of above a dozen faculty members' team - the USC Rossier School of Education cooperative (USC Rossier School, 2020). The role of leadership in schools throughout the COVID -19 conditions has been emphasized by (Harris, 2020).

According to (Garrison \& Arbaugh, 2007) teachers thought that introducing several learning management tools rapidly was not helpful, additionally, ERTEs were considered more successful by participants when having enough time in learning the needed technologies (Garrison \& Arbaugh, 2007).

In most cases, lack of experience was the main reported obstacle universities faced in the handling of the COVID19 emergency taking into consideration the uniqueness of the COVID-19 compared to natural disasters (Hodges et al, 2020). The anticipated changes cover changing the forms, constructions, teaching practices, science, and social contribution as clarified by (Izumi et al, 2020).

\section{Research Questions}

The chief research question is Do all the investigated universities websites' offered services / transactions reflect being proactive and rapid responses toward the COVID-19 crisis or not? The answer of this question is attained by conducting experiments on their websites and answering three questions throughout two phases as:

Phase 1 -Research Question1 (RQ1): What are the ranks of the investigated universities' websites based on the association with the presented information on their websites regarding information criteria (Accurate, Completed and Updated)?

Phase 2 -Research Question1 (RQ2)

What are the statuses of the investigated universities' websites based on how long it took till found on-line admission / apply on-line?

Phase 2 -Research Question2 (RQ3)

What are the ranks of the investigated universities' websites based on how long it took till the process of on-line admission / applying on-line is completed?

\section{Research Methods}

In this research quantitative experimental was applied on 16 national and private universities' websites (61.5\%), out of 26 universities in June 2020 based on (Information and Decision Support Center System, 2020c). The 
examined universities websites were randomly nominated. The data was collected through three rounds. A conceptual model of the study detailing stages is demonstrated in Figure 1 below. The data collection was mainly through inviting candidates IG and American diploma graduates on social media groups to participate in the experiment. The candidates seeking information about national and private universities and applying on-line. The data was collected by three rounds trying to extend the participants' number of the experiment.

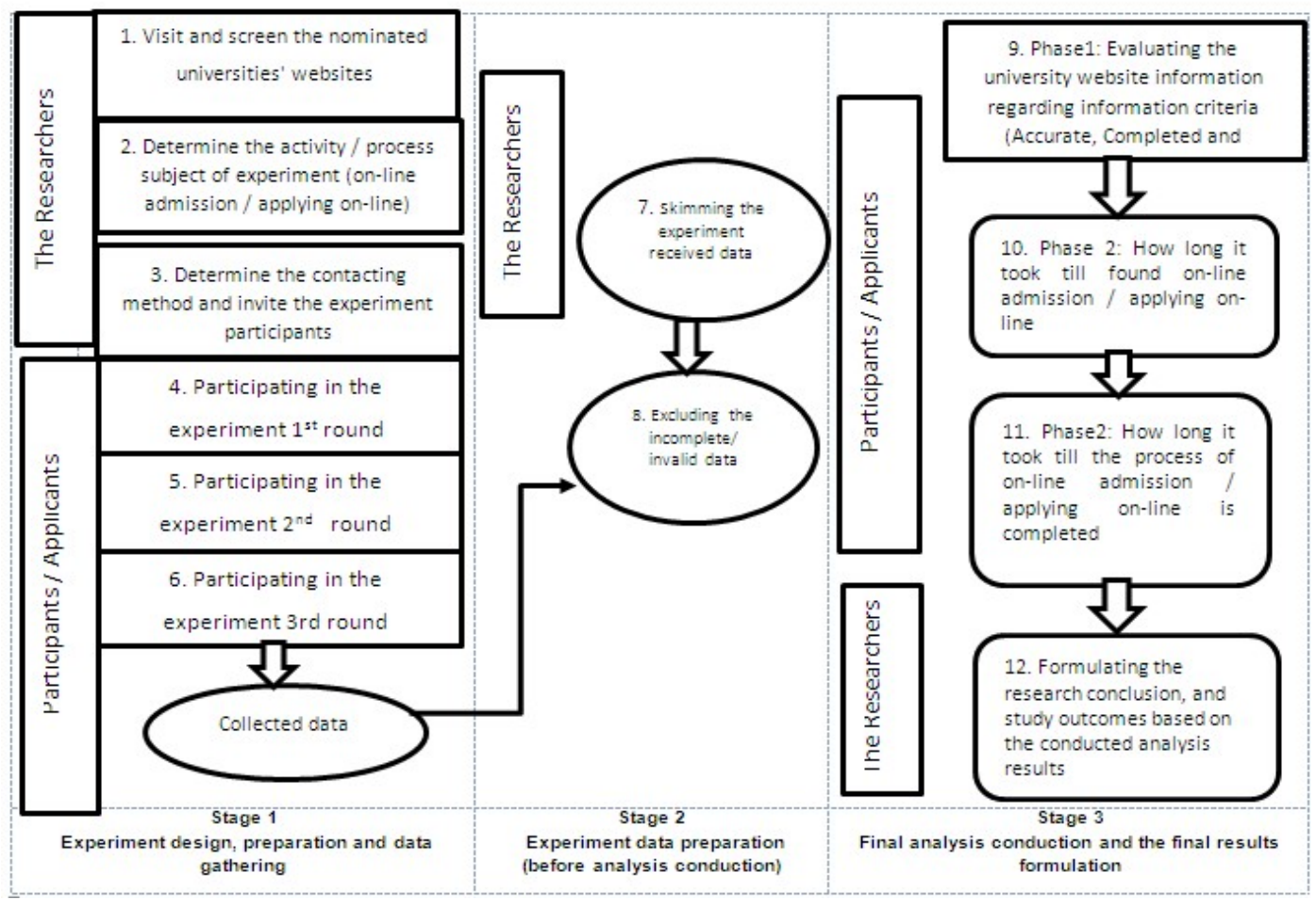

Figure 1 Conceptual Model of the Study Detailing Stages

Adapted from Source: (Gupta \& Verma, 2019)

\section{Research Conducted Analysis and Findings}

The experiment participants described in terms of the certificate category and gender are offered in Table 1 below, most of the participants were IG graduates $(71.2 \%)$ with almost equal male and female gender distribution.

\begin{tabular}{|l|l|l|l|}
\hline \multicolumn{4}{|c|}{ Table 1 Certificate Category and Gender Frequency and Percent \% } \\
\hline & & Frequency & Percent \% \\
\hline Certificate & American & 21 & $28.8 \%$ \\
\cline { 2 - 4 } & IG & 52 & $71.2 \%$ \\
\hline Gender & Female & 36 & $49.3 \%$ \\
\cline { 2 - 4 } & Male & 37 & $50.7 \%$ \\
\hline & Total & 73 & $100.0 \%$ \\
\hline
\end{tabular}


Figure 2 below shows the frequencies and percent \% distribution of the experiments participants according to experiments conduction dates. The dates ranged from $1^{\text {st }}$ of July to 18 of August.

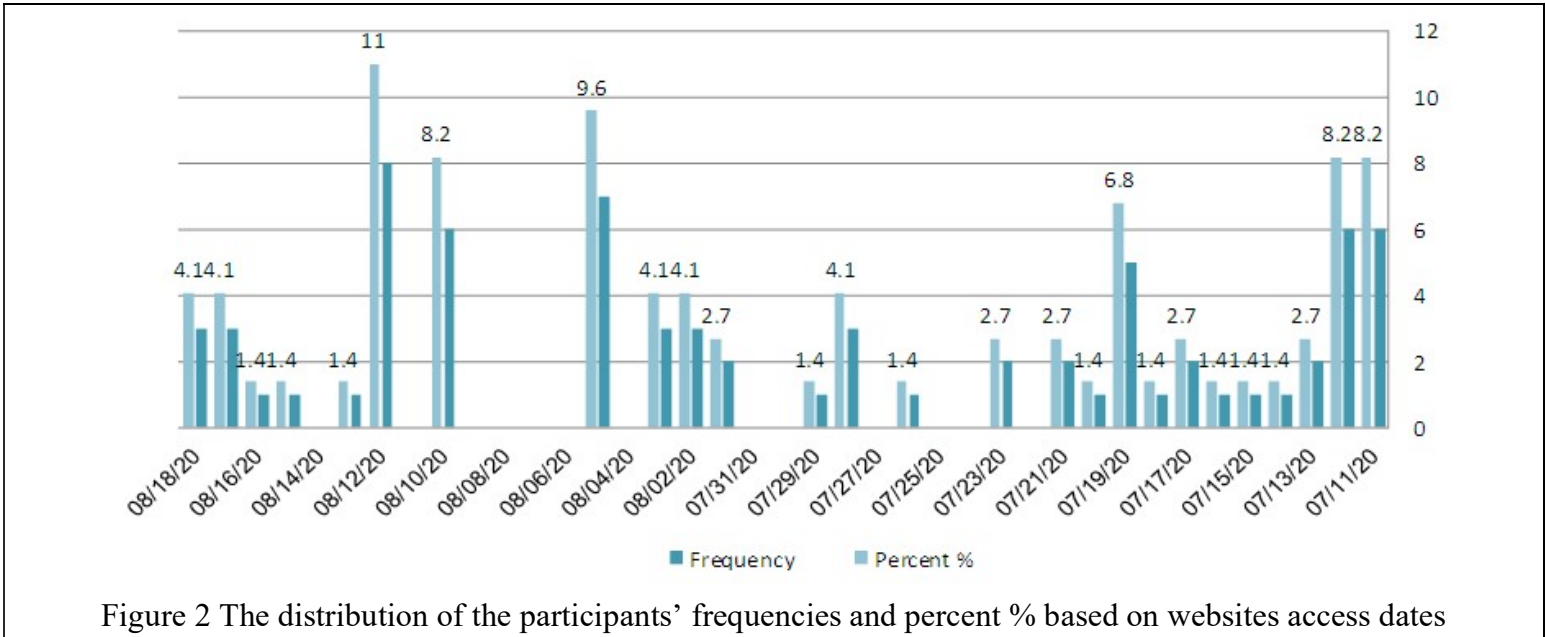

Concerning the chief research question Do all the investigated universities websites' offered services / transactions reflect being proactive and rapid responses toward the COVID-19 crisis or not?

The answer: almost all of the investigated universities websites provide number of services / transactions through their websites with fluctuated levels of being proactive and rapid responses toward the COVID-19. The following sections present more clarifications with answering of the previously stated research questions.

\section{Phase 1 -Research Question1 (RQ1)}

Concerning RQ1 what are the ranks of the investigated universities' websites based on the association with the presented information on their websites regarding information criteria- Accurate, Completed and Updated?

The average was adopted to rank the examined websites. As table 1 demonstrated, $99.7 \%$ was the highest average value (UW9) 1st rank and the lowest average value was 65\% (UW2) rank number 12, six websites shared the 2 nd and 3 rd ranks distributed as 2 and 4 websites with order respect.

Table 1 Certificate Category and Gender Frequency, Percent, and Cumulative Percent

\begin{tabular}{|c|c|c|c|c|c|c|c|c|}
\hline University Name and Website & $\begin{array}{l}\text { Update } \\
\text { d }\end{array}$ & $\%$ & Completed & $\%$ & $\begin{array}{l}\text { Accur } \\
\text { ate }\end{array}$ & $\%$ & Average & Rank \\
\hline $\begin{array}{l}6 \text { th October } \\
\text { UW1:https://o6u.edu.eg/default.asp } \\
d=70\end{array}$ & 72 & $99 \%$ & 68 & $93 \%$ & 70 & $96 \%$ & $96 \%$ & 8 \\
\hline $\begin{array}{l}\text { Al-Ahram Canadian } \\
\text { UW2:http://www.acu.edu.eg/en/ }\end{array}$ & 67 & $92 \%$ & 6 & $8 \%$ & 69 & $95 \%$ & $65.0 \%$ & 12 \\
\hline $\begin{array}{l}\text { The Arab Open University (AOU) } \\
\text { UW3: http://www.aou.edu.eg/ }\end{array}$ & 72 & $99 \%$ & 73 & $100 \%$ & 69 & $95 \%$ & $98.0 \%$ & 4 \\
\hline Nile University & 70 & $96 \%$ & 73 & $100 \%$ & 73 & $100 \%$ & $98.7 \%$ & 2 \\
\hline
\end{tabular}




\begin{tabular}{|c|c|c|c|c|c|c|c|c|}
\hline \multicolumn{9}{|l|}{ UW4:https://nu.edu.eg// } \\
\hline $\begin{array}{l}\text { Egyptian e-Learning University } \\
\text { (EELU) }\end{array}$ & 73 & $100 \%$ & 69 & $95 \%$ & 73 & $100 \%$ & $98.3 \%$ & 3 \\
\hline \multicolumn{9}{|l|}{ UW5: http://www.eelu.edu.eg/ } \\
\hline Future University in Egypt & 69 & $95 \%$ & 73 & $100 \%$ & 73 & $100 \%$ & $98.3 \%$ & 3 \\
\hline \multicolumn{9}{|l|}{ UW6: https://www.fue.edu.eg/ } \\
\hline $\begin{array}{l}\text { Misr University for Science \& } \\
\text { Technology (MUST) }\end{array}$ & 72 & $99 \%$ & 73 & $100 \%$ & 71 & $97 \%$ & $98.7 \%$ & 2 \\
\hline \multicolumn{9}{|l|}{ UW7: https://www.must.edu.eg/ } \\
\hline $\begin{array}{l}\text { October University for Modern } \\
\text { Sciences and Arts - MSA University }\end{array}$ & 68 & $93 \%$ & 67 & $92 \%$ & 71 & $97 \%$ & $94.0 \%$ & 10 \\
\hline Badr University in Cairo & 72 & $99 \%$ & 73 & $100 \%$ & 73 & $100 \%$ & $99.7 \%$ & 1 \\
\hline $\begin{array}{l}\text { The German University in Cairo } \\
\text { (GUC) }\end{array}$ & 71 & $97 \%$ & 72 & $99 \%$ & 70 & $96 \%$ & $97.3 \%$ & 6 \\
\hline \multicolumn{9}{|l|}{ UW10: https://www.guc.edu.eg/ } \\
\hline Pharos University In Alexandria (PUA) & 70 & $96 \%$ & 70 & $96 \%$ & 69 & $95 \%$ & $95.7 \%$ & 9 \\
\hline The British University In Egypt (BUE) & 69 & $95 \%$ & 72 & $99 \%$ & 71 & $97 \%$ & $97 \%$ & 7 \\
\hline Heliopolis University & 70 & $96 \%$ & 73 & $100 \%$ & 71 & $97 \%$ & $97.7 \%$ & 5 \\
\hline Nahda University & 72 & $99 \%$ & 70 & $96 \%$ & 73 & $100 \%$ & $98.3 \%$ & 3 \\
\hline Sinia University & 69 & $95 \%$ & 73 & $100 \%$ & 73 & $100 \%$ & $98.3 \%$ & 3 \\
\hline Misr International University (MIU) & 68 & $93 \%$ & 66 & $90 \%$ & 67 & $92 \%$ & $91.7 \%$ & 11 \\
\hline UW16:http://www.miuegypt.edu.eg/ & & & & & & & & \\
\hline
\end{tabular}

Phase 2 -Research Question1 (RQ2)

\section{Concerning RQ2 what are the statuses of the investigated universities' websites based on how long it took till} found on-line admission / apply on-line?

The frequent time in seconds, minimum, maximum, mean, and std. deviation functions were adopted as Table 2 showed, taking in consideration that zero (0) value appeared in the most frequent time in seconds column (seven websites) in case of the automatically- by default (not based on a website visitor request) display of the on-line admission / applying on-line the websites. Five universities websites required only one second for finding on-line 
admission / applying on-line option. Followed by two websites required two and four seconds, the longest times in seconds required were for two universities websites recoded 50 and 60 seconds. Figure 3 displayed histograms for the examined universities websites' mean, and Std. Deviation values for applying on-line process time.

Table 2 Universities Websites Most Frequent Time In Seconds, Range, Minimum, Maximum, Mean In Seconds, and Std. Deviation

\begin{tabular}{|c|c|c|c|c|c|c|}
\hline $\begin{array}{l}\text { University } \\
\text { Website \# }\end{array}$ & $\begin{array}{l}\text { Most Frequent Time } \\
\text { In Seconds }\end{array}$ & Range & Minimum & Maximum & $\begin{array}{c}\text { Mean } \\
\text { In Seconds }\end{array}$ & Std. Deviation \\
\hline UW1 & 0 & 0 & 0 & 0 & .00 & .000 \\
\hline UW2 & 4 & 2 & 3 & 5 & 4.15 & .720 \\
\hline UW3 & 1 & 1 & 1 & 2 & 1.26 & .442 \\
\hline UW4 & 1 & 1 & 1 & 2 & 1.21 & .407 \\
\hline UW5 & 60 & 36 & 30 & 66 & 51.67 & 7.904 \\
\hline UW6 & 1 & 1 & 1 & 2 & 1.19 & .396 \\
\hline UW7 & 0 & 0 & 0 & 0 & .00 & .000 \\
\hline UW8 & 0 & 0 & 0 & 0 & .00 & .000 \\
\hline UW9 & 0 & 0 & 0 & 0 & .00 & .000 \\
\hline UW10 & 50 & 76 & 4 & 80 & 53.07 & 11.698 \\
\hline UW11 & 0 & 0 & 0 & 0 & .00 & .000 \\
\hline UW12 & 1 & 2 & 1 & 3 & 1.38 & .568 \\
\hline UW13 & 2 & 2 & 1 & 3 & 2.19 & .638 \\
\hline UW14 & 0 & 0 & 0 & 0 & .00 & .000 \\
\hline UW15 & 1 & 2 & 1 & 3 & 1.12 & .371 \\
\hline UW16 & 0 & 0 & 0 & 0 & .00 & .000 \\
\hline
\end{tabular}
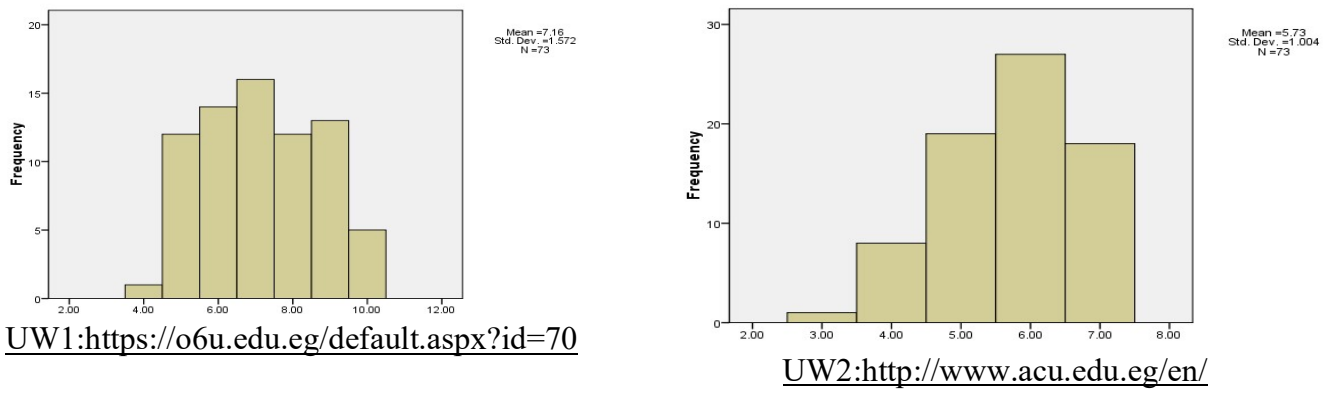

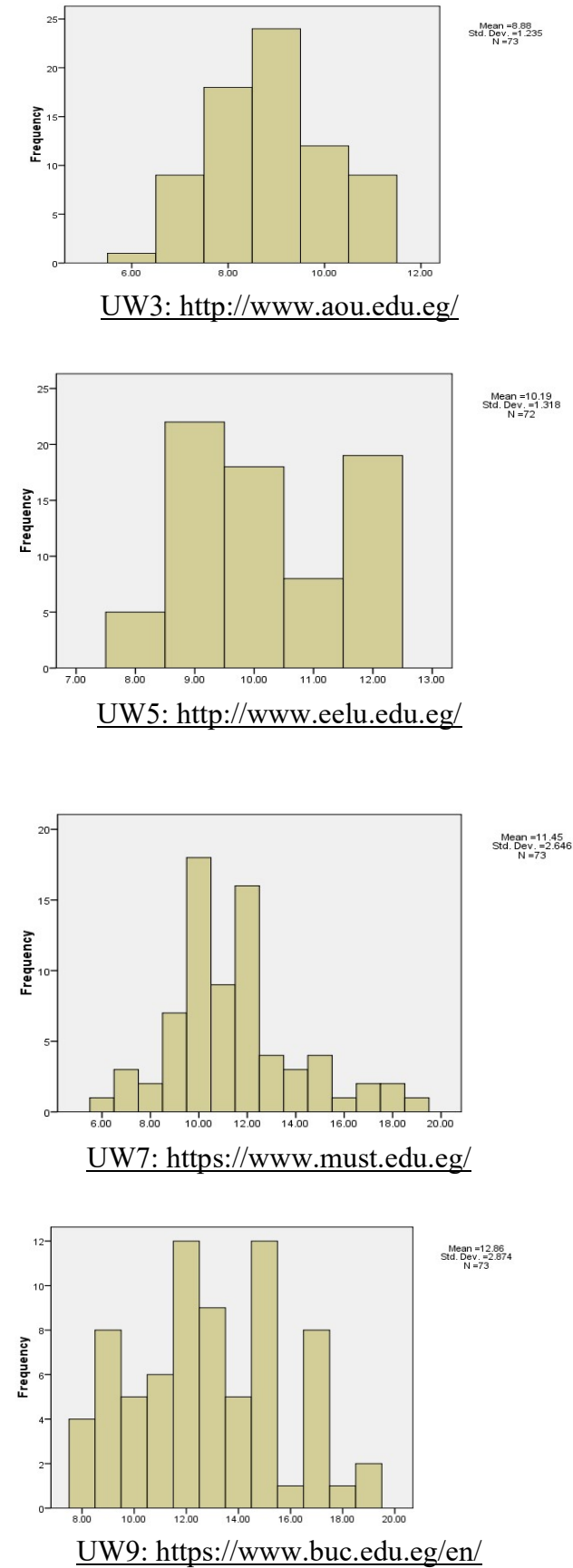

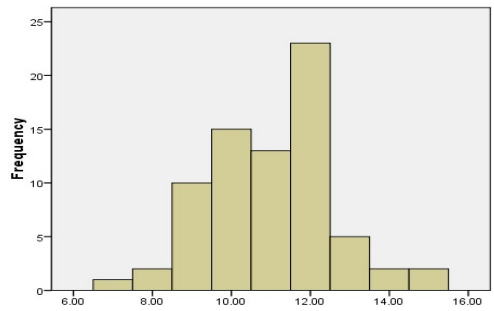

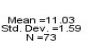

UW4:https://nu.edu.eg//

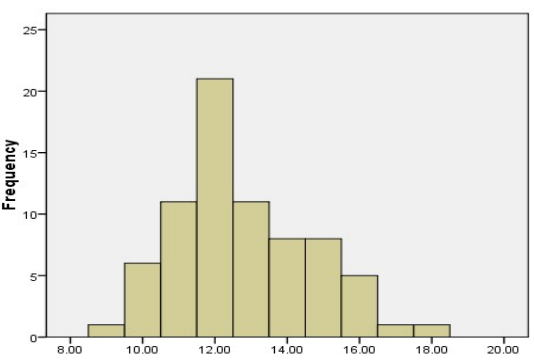

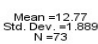

UW6: https://www.fue.edu.eg/

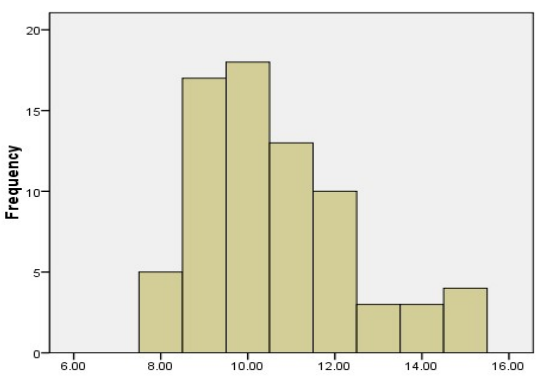

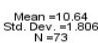

UW8:https://msa.edu.eg/msauniversity/

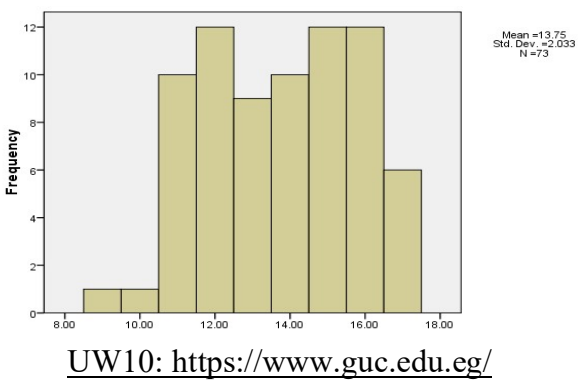




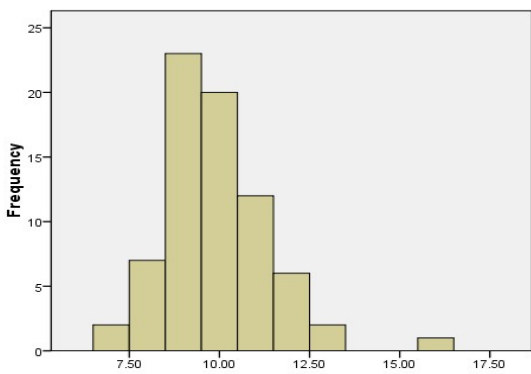

$\substack{\text { Mean } \\ \text { std. Dev } \\ N=7}$
$N=7$

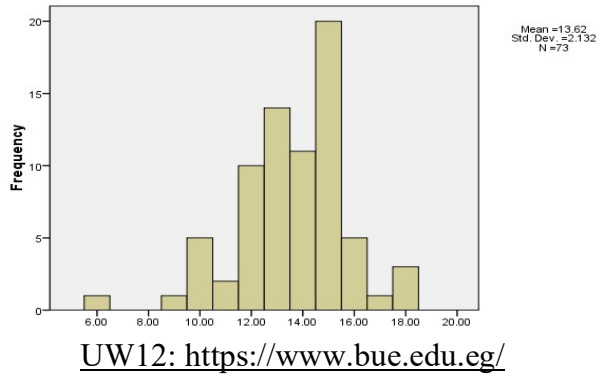

UW11: https://www.pua.edu.eg/

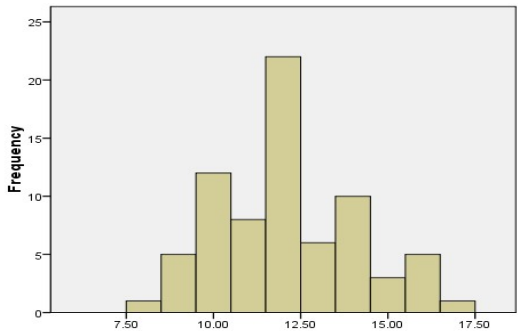

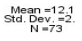

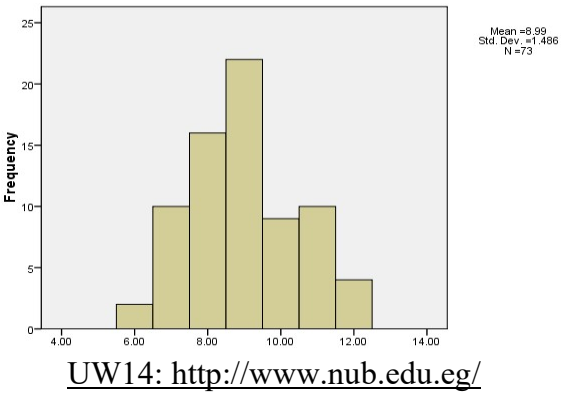

UW13: https://www.hu.edu.eg/
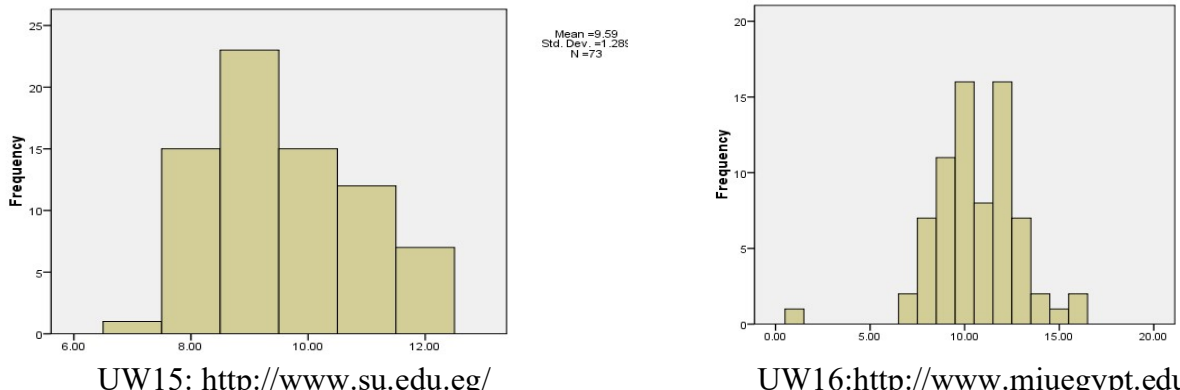

Mean
sta. $=10.63$
SeV
$N-7=2.276$

UW16:http://www.miuegypt.edu.eg/

Figure 3 Histograms for the examined universities websites', mean, and std.dev values for applying online process time

* The investigated universities names and websites

*Source: (Ministry of Higher Education and Scientific Research, 2020)

Phase 2 -Research Question2 (RQ3)

Concerning RQ3 what are the ranks of the investigated universities' websites based on how long it took till the process of on-line admission / applying on-line is completed?

Based on Table 3, that presents universities' websites ranks based on most frequent time in minutes for applying on-line process, min, max, variance range, and mean in minutes, and std. dev. values. The most frequent times ranged from 6:16 minutes, and from 1: 16 for the minimum and maximum required times. Some universities websites have two values regarding the most frequent time in minutes as in case of UW 9, UW10, and UW 16. 


\begin{tabular}{|c|c|c|c|c|c|c|c|}
\hline University Website \# & $\begin{array}{l}\text { Most Frequent } \\
\text { Time In } \\
\text { Minutes }\end{array}$ & Minimum & Maximum & Range & $\begin{array}{c}\text { Mean } \\
\text { In Minutes }\end{array}$ & $\begin{array}{c}\text { Std. } \\
\text { Deviation }\end{array}$ & Rank \\
\hline UW1 & 7 & 4 & 10 & 6 & 7.16 & 1.572 & 2 \\
\hline UW2 & 6 & 3 & 7 & 4 & 5.73 & 1.004 & 1 \\
\hline UW3 & 9 & 6 & 11 & 5 & 8.88 & 1.235 & 3 \\
\hline UW4 & 12 & 7 & 15 & 8 & 11.03 & 1.59 & 10 \\
\hline UW5 & 9 & 8 & 12 & 4 & 10.19 & 1.318 & 7 \\
\hline UW6 & 12 & 9 & 18 & 9 & 12.77 & 1.889 & 13 \\
\hline UW7 & 10 & 6 & 19 & 13 & 11.45 & 2.646 & 11 \\
\hline UW8 & 10 & 8 & 15 & 7 & 10.64 & 1.806 & 9 \\
\hline \multirow[t]{2}{*}{ UW9 } & 12 & 8 & 19 & 11 & 12.86 & 2.874 & 14 \\
\hline & 15 & 8 & 19 & 11 & 12.86 & 2.874 & 14 \\
\hline \multirow[t]{2}{*}{ UW10 } & 15 & 9 & 17 & 8 & 13.75 & 2.033 & 16 \\
\hline & 16 & 9 & 17 & 8 & 13.75 & 2.033 & 16 \\
\hline UW11 & 9 & 7 & 16 & 9 & 9.90 & 1.483 & 6 \\
\hline UW12 & 15 & 6 & 18 & 12 & 13.62 & 2.132 & 15 \\
\hline UW13 & 12 & 8 & 17 & 9 & 12.12 & 2.02 & 12 \\
\hline UW14 & 9 & 6 & 12 & 6 & 8.99 & 1.486 & 4 \\
\hline UW15 & 9 & 7 & 12 & 5 & 9.59 & 1.289 & 5 \\
\hline \multirow[t]{2}{*}{ UW16 } & 10 & 1 & 16 & 15 & 10.63 & 2.276 & 8 \\
\hline & 16 & 1 & 16 & 15 & 10.63 & 2.276 & 8 \\
\hline
\end{tabular}

Table 4 below shows the universities' websites aggregate ranks - columns 3 considering the time required to find applying on-line option and column 6 considering the process conduction required time. These ranks were based on most frequent time in minutes, and means for finding in columns 1 and 2 and applying on-line process conduction in columns 4 and 5. The universities' websites that automatically display on-line admission / applying on-line facility; without selecting were excluded from the ranks list of the universities' websites (UW7, UW8, UW9, UW11, UW14, and UW16). On the other hand, the time was considered for the universities that display online admission / applying on-line in their websites upon selecting or using a search facility. Universities websites' ranked regarding the time consumption of the process. Some universities websites' retained almost the same top ranks in both searching for on-line admission / applying on-line facility and applying online processes like in case of such as UW15 got the $1^{\text {st }}$ rank in both. The same noted for the average /moderate positions where some universities' websites received almost the same ranks such as in case of UW3 and UW5. 
Table 4 Universities' websites aggregate ranks based on most frequent time in minutes, and means for finding apply on-line and conducting the processes

\begin{tabular}{|c|c|c|c|c|c|c|}
\hline & \multicolumn{3}{|c|}{ Finding on-line admission / applying on-line process } & \multicolumn{3}{|c|}{ Applying on-line process } \\
\hline & 1 & 2 & 3 & 4 & 5 & 6 \\
\hline University Website \# & $\begin{array}{c}\text { Most Frequent Time } \\
\text { In Seconds }\end{array}$ & $\begin{array}{c}\text { Mean } \\
\text { In Seconds }\end{array}$ & $\begin{array}{c}\text { Rank based on } \\
\text { Mean Time in } \\
\text { Seconds (5) }\end{array}$ & $\begin{array}{l}\text { Most Frequent } \\
\text { Time In Minutes }\end{array}$ & $\begin{array}{c}\text { Mean } \\
\text { In Minutes }\end{array}$ & $\begin{array}{l}\text { Rank based on } \\
\text { Mean Time in } \\
\text { Minutes } \\
\text { (2) }\end{array}$ \\
\hline$U W 1$ & 0 & .00 & & 7 & 7.16 & 2 \\
\hline UW2 & 4 & 4.15 & 7 & 6 & 5.73 & 1 \\
\hline UW3 & 1 & 1.26 & 4 & 9 & 8.88 & 3 \\
\hline UW4 & 1 & 1.21 & 3 & 12 & 11.03 & 10 \\
\hline UW5 & 60 & 51.67 & 8 & 9 & 10.19 & 7 \\
\hline UW6 & 1 & 1.19 & 2 & 12 & 12.77 & 13 \\
\hline UW7 & 0 & .00 & & 10 & 11.45 & 11 \\
\hline UW8 & 0 & .00 & & 10 & 10.64 & 9 \\
\hline UW9 & 0 & .00 & & 12 & 12.86 & 14 \\
\hline & 0 & .00 & & 15 & 12.86 & 14 \\
\hline UW10 & 50 & 53.07 & 9 & 15 & 13.75 & 16 \\
\hline & 50 & 53.07 & 9 & 16 & 13.75 & 16 \\
\hline UW11 & 0 & .00 & & 9 & 9.90 & 6 \\
\hline UWI2 & 1 & 1.38 & 5 & 15 & 13.62 & 15 \\
\hline UW13 & 2 & 2.19 & 6 & 12 & 12.12 & 12 \\
\hline
\end{tabular}




\begin{tabular}{|c|c|c|c|c|c|c|}
\hline UW15 & 1 & 1.12 & 1 & 9 & 9.59 & 5 \\
\hline UWI6 & 0 & .00 & & 16 & 10.63 & 8 \\
\hline
\end{tabular}

\section{Research Discussion and Implication}

The conducted experiments during the COVID-19 crisis on 16 universities' websites revealed a respected concern of the universities to keep their websites informative with clear, accurate, and most recent information. This was clarified in (Peterson et al, 2020) who stressed considering the up- to- date information as well as user needs. These universities were alerted to the COVID -19 crisis impact on their offered services and core activities. This goes in the same direction as what was reported by (Hilburg et al, 2020) on the subject of the COVID -19 impact on medical education at both undergraduate and graduate levels whether it's organization or delivery. As (Izumi et al, 2020) mentioned that the anticipated adjustments are not limited to changing the forms, constructions, and teaching practices but also cover science and social contribution. This practice is aligned with (Bao, 2020) who stressed that solutions can't be given until contingency plans development took a place. Most universities have experience deficiency in dealing with the emergency of the COVID-19 as a suffering obstacle (Izumi et al, 2020). Although the fluctuated positions of some examined universities' websites regarding the conduced process (applying online) examination, furthermost of them remain almost the same ranks in the experiment phases. Bearing in mind that no obvious relationships concluded between the consumed times for searching for on-line admission/applying on-line facility and applying online processes, which makes it not easy to rank the universities' websites considering the search for the on-line admission/applying on-line facility and applying online as well. Common with the view offered by (Hilburg et al, 2020) concerning the effect of the COVID -19 on the structure and supply forms.

To conclude, the decision-makers in universities advised reordering their priorities and strategies considering crisis created needs. Having their websites dynamically in the response to emergencies such as the COVID-19 crisis is critical to some extent. Having the same direction of the remarkable of the contingency plans development (Bao, 2020). Conducting crisis plan activities regularly is essential in case of being proactive. This among the set of actions required to mitigate the negative impact and risks associated with such a crisis. Examples of such anticipated variations and adjustments were provided by (Izumi et al, 2020). Accordingly, more attention should be paid to benefit from information technology capabilities, enhance and upgrade their websites, and keep a regular modification for their websites to be informative, clear, and recent as well. An adoption rise during the COVID19 in the technology-based tool - solutions that enabled connections between learners was stated by (Zhu et al, 2020). The technological support that may offer an alternative such as distance learning as a mandatory option even with its social side associated issue (Kennedy \& Ferdig, 2018 ). The unlikeness of the social associated issue makes the usual handlings, not an appropriate option in this case as (Bao, 2020) explained.

\section{Research Limitations and Future Work Directions}

None of the education entities including universities didn't tried to be highly responsive during the COVID-19 pandemic. In HE sector, universities websites are key gates for the current and potential students which mandate keeping the websites always up-to-date, informative, and accurate. The universities that succeeded in this process may be applied crisis management although this may challenge by lack of updated emergencies plans and /or inexperienced staff, which might be a theme of more needed researches.

The review of the early researches and the conducted experiments outcomes previously offered support initializing investigations concerns universities portals and homepages. Aim at building a road map for continuous enhancing and maintaining of them considering the outcomes of such studies. Emergences and crises make new needs to 
fulfill within tied time frame- a restricted constraint. The innovations and technologies are concerning obviously in the HE sector. This may help in replying inquiries about main entities associated with the HE such universities.

Evaluation of universities websites concerning the enables online functions is needed with the e-learning wave essentially that is a subgroup of the HE core structures as reported In (Harris, 2020). The universities websites developers should consider the studies and conducted analysis outcomes when they draw down their innovations and enhancements projects. This practice may assist in decrease the risks associated with misunderstanding of the portals users and visitors desired.

\section{References}

Abd El Halim, H. (2019) Investigating Tools Selection, Adoption Intention, and Acceptance of Computer Technology in Private Higher Education in Egypt: Project Management Software Casual End-User Perspective. Journal of Alexandria University for Administrative Sciences, 56 (1), 1-20.

Bao, W. (2020) COVID-19 and online teaching in higher education: a case study of Peking University, Human Behavior and Emerging Technologies, 2:113-115

Garrison, D.R. \& Arbaugh, J.B.,( 2007) Researching the community of inquiry framework: review, issues, and future directions, The Internet and Higher Education, pp. 157-172.

Gupta, S. \& Verma, H.V. (2019) Mindfulness, mindful consumption, and life satisfaction: An experiment with higher education students, Journal of Applied Research in Higher Education, 456-474. .

Harris, A. (2020) COVID-19 - school leadership in crisis? , Journal of Professional Capital and Community, ahead-of-print. 2020. DOI 10.1108/JPCC-06-2020-0045.

Hendal, B.A. (2020) Kuwait University faculty's use of electronic resources during the COVID-19 pandemic, Digital Library Perspectives, ahead-of-print, 2020. DOI :10.1108/DLP-04-2020-0023

Hilburg R. et al, (2020) Medical Education During the COVID-19 Pandemic: Learning From A Distance, Advances in Chronic Kidney Disease, 05.017

Hodges, C. et al, (2020) The difference between emergency remote teaching and online learning, EDUCAUSE Review., 102-113

Information and Decision Support Center System ,Statistics And Indicators, Information And Statistics(2020a), Total number of students enrolled in private universities (Student) https://www.idsc.gov.eg/IDSC/DMS/View.aspx?id=2334\&amp;cid=0 (accessed: 21 July 2020)

Information and Decision Support Center System Statistics And Indicators, Information And Statistics (2020b), Number of private universities (University) https://www.idsc.gov.eg/IDSC/DMS/View.aspx?id=1833\&cid=0 (accessed: 21 August 2020)

Information and Decision Support Center System, Statistics And Indicators, Information And Statistics (2020c), https://www.idsc.gov.eg/IDSC/DMS/View.aspx?id=1833\&cid=0. (Accessed: 13 July 2020)

Izumi, T., Sukhwani, V., Surjan, A. \& Shaw, R.(2020) Managing and responding to pandemics in higher educational institutions: initial learning from COVID-19, International Journal of Disaster Resilience in the Built Environment, ahead-of-print 16 Jul 2020. DOI: 10.1108-06-2020-0054

Kennedy, K. \& Ferdig, R.E. (2018) (Eds.). Handbook of Research of K12 Online and Blended Learning $2^{\text {nd }}$ ed. Pittsburgh, PA: Carnegie Mellon University: pp.738

Lehman, R. M., \& Conceicao, S. C. (2010) Creating a Sense of Presence in Online Teaching: How To Be There for Distance Learners, San Francisco, CA: Jossey-Bass Journal of Creative Education, Vol.7 No.5 
Maxwell Library, Bridge water State University. Coronavirus and Maxwel 1library,(2020) https://library.bridgew.edu/Coronvirus-and-Library-Services.( accessed: 12 July 2020)

Mehta, D. \& Wang, X. (2020) COVID-19 and digital library services - a case study of a university's library, Digital Library Perspectives, ahead-of-print, DOI: 10.1108-05-2020-0030

Ministry of Higher Education and Scientific Research (2020),http://portal.mohesr.gov.eg/ar-eg/Pages/privateuniversities.aspx (accessed: 9 July 2020)

Peterson, L., Scharber, C., Thuesen, A. \& Baskin, K. (2020) A rapid response to COVID-19: one district's pivot from technology integration to distance learning, Information and Learning Sciences, 461-469

Rice, K. \& Kipp, K. ( 2020) How can educators tap into research to increase engagement during remote learning?, EdSurge, available at: www.edsurge.com/news/2020-05-06-how-caneducators- tap-into-research-to-increaseengagement-during-remote-learning ( accessed 23 July 2020).

Sawyer, R.K.(Ed.) (2005) Introduction : the new science of learning, The Cambridge Hand book of the Learning Sciences, $2^{\text {nd }}$.ed., Cambridge University Press., p. 42.

Trust, T. (2020) Emergency remote teaching vs. quality online teaching, YouTube video, available at: www.youtube.com/watch?v=1GdpMldtoXU\&amp;feature=youtu.be (accessed 7 august 2020).

USC Rossier School of Education supporting online learning in a time of pandemic (2020), USC Rossier, April 13

Whittle, C., Tiwari, S., Yan, S. \& Williams,J (2020). Emergency remote teaching environment: a conceptual framework for responsive online teaching in crises, Information and Learning Sciences, 311-319.

Xu, D., Li, Q., \& Zhou, X. (2020) Online Course Quality Rubric: A Tool Box. Online Learning Research Center, University of California, Irvine, https:/www.olrc.us/reflecting-on-course-design.html(accessed: 17 July 2020)

Zhu, X., et al, (2020) Reading and connecting: using social annotation in online classes, Information and Learning Sciences, 261-271. 